\title{
Insufficient Higher Order Thinking Skill in Reading Comprehension Exercises of an English Language Textbook
}

\author{
Gracia Putri Sang Dewayani \\ gracia.ft@gmail.com \\ Ngadiso \\ ngadisodok@yahoo.com \\ Teguh Sarosa \\ teguhsrs@staff.uns.ac.id \\ Universitas Sebelas Maret
}

\begin{abstract}
Higher order thinking skill (HOTS) is an important outcome standard of higher education in any discipline. Accordingly, English language textbook should present higher order thinking questions to promote students' higher order thinking skill. The aim of this research is to analyze the extent to which the higher order thinking skill (HOTS) and the indicators of reading skill are assessed in the reading comprehension exercises. This research used the descriptive analytical method of research, which refers to content analysis. The data are analyzed based on revised Bloom's taxonomy and reading skill indicators. The findings reveal that: (1) HOTS in the reading comprehension exercises questions only includes analyzing skill and evaluating skill while creating skill is not found; and (2) the indicators of reading skill are not fully assessed from the questions in the reading comprehension exercises in English language textbook for twelfth grade students by Indonesian Ministry of Education and Culture. The textbook only assesses topic, explicit meaning, and implicit meaning indicators. Students will not achieve higher order thinking skill and reading skill excellently if they only practice reading comprehension exercises from the textbook.
\end{abstract}

Keywords: higher order thinking skill, reading skill, textbook, content analysis.

\section{INTRODUCTION}

In this $21^{\text {st }}$ century, education must be capable to form competent students to be skillful to meet the demands of the development of science and technology in the industrial world. Students must enhance skills and improve learning to be capable to overcome global challenges, such as critical thinking skill, ability to communicate effectively, innovation, and problem solving through negotiation and collaboration (Saavedra in Maulia et al, 2018). One of the efforts of the Indonesian government to respond to this global challenge is by revising regulation for making a lesson plan to match the needs of the era. In the Minister of Education and Culture Regulation no. 22 in 2016 which regulates basic and secondary education standards, teachers in making lesson plan must contain 4 things in teaching and learning, they are: integrate character education (religious, nationalist, independent, mutual cooperation and integrity), integrate literacy, integrate $4 \mathrm{C}$ (creative, critical thinking, communicative and collaborative), and integrate HOTS (Higher Order Thinking Skill). To help teachers bring these things into the learning process, the 
government also publishes a revised version of the electronic schoolbook (BSE) to adjust to the new regulations which are believed to be a reference for teachers in the teaching and learning process. Therefore, the contents and exercises in the English language textbook should stimulate students' higher order thinking skill (HOTS) where they are not only given lessons and exercises in the areas of lower order thinking skill (LOTS). Anderson and Krathwhol (2001) stated that lower order thinking skill (LOTS) consists of C1 (remembering), C2 (understanding), and C3 (applying) then higher order thinking skill (HOTS) consists of C4 (analyzing), C5 (evaluating), and C6 (creating).

An applicable English textbook must contain relevant reading text followed by reading exercises. The exercises of reading text can determine the proficiency of students' comprehension by using the instruments of reading comprehension (Cunningsworth, 1998). Questions for reading comprehension exercises in English textbook will be able to prove the implementation of the curriculum used in Indonesia at this time. Thus, reading exercises and questions presented in English language textbook by the government must contain questions that involve higher order thinking skill to answer and lead students to be able to critically understand texts as suggested by the English syllabus from the curriculum 2013 version revised by the government. Moreover, the questions in the reading exercises should assess all of the indicators of reading skill so that students can achieve a great reading skill. Reading comprehension exercises are important to contain higher order thinking skill and the indicators of reading skill since cognitive skill are the basis of the whole learning process. Students will have good reading skill if they have high cognitive skill. Students who do not use HOTS are typically have low reading skill (Marier, 2000).

Assaly and Smadi (2015) evaluated the cognitive levels of the questions following the reading texts of Master Class. The findings showed that about $40 \%$ of the textbook's questions emphasized higher order thinking skill. Ulum (2016) analyzed to what extent Bloom's Taxonomy is intended to in reading comprehension exercises questions of English as a Foreign Language textbook. This research finds that the book is lack of higher level thinking skill, the textbook only develops key cognitive skills such as remembering and understanding. Chalak and Mizbani (2017) evaluated reading and writing activities of the textbook used for Iranian Junior High School third-graders based on Bloom's Revised Taxonomy of cognitive domain to examine in which category of a lower level or a higher level of the learning activities purposes are classified. The findings showed that the reading and writing activities of the textbook were mostly categorized in the lower levels based on the learning objectives of the cognitive domain. Al Raqad and Ismail (2018) analyzed the lower and higher order thinking skills of reading comprehension questions in the Action Pack 12 English language textbook for grade twelve students in Jordan. The findings showed that out of 104 reading comprehension questions there are only 35 higher order thinking questions. San (2019) investigated the levels of thinking demanded by reading tasks in the coursebook Global A2+. The findings revealed that the majority of the questions assessed the lower order thinking skill and only a few questions were found to address higher order thinking skill.

The research gaps are the theorist and contextual gap. What makes this research different from the other research is that no researchers are analyzing the English language textbook for twelfth grade students by the Indonesian Ministry of Education and Culture. In addition, some of the researchers are still using the first version of Bloom's Taxonomy as the basis for analysis, while in this research the researcher used the latest revised edition of Bloom's Taxonomy.

The aim of this research is analyzing the availability of higher order thinking skill (HOTS) in the reading comprehension exercises questions in the English language textbook for twelfth grade students by the Indonesian Ministry of Education and Culture to obtain 
the empiric data of the distribution of the higher order thinking skill based on the revised version of Bloom's Taxonomy. It is also to analyze the extent to which the reading comprehension exercises in the textbook assess the indicators of reading skill.

\section{LITERATURE REVIEW}

\section{English Textbook}

English language textbook for twelfth grade students by the Indonesian Ministry of Education and Culture have a role as an important teaching resource for teachers in the teaching and learning process. Airasian and Russel (2008) claimed, "English textbook is a learning resource that gives a big influence on what teaching and learning is carried out in the classroom. The textbook also greatly influences the planning and the implementation of a learning process in the classroom." The English textbook is a resource that gives significant influences in the teaching and learning practice since it is considered as an instructional plan for teachers in teaching the students in the classroom. They also stated that the teachers' teaching resources affect several significant things, namely the teaching style character, learning activity, and learning result. Therefore, textbook evaluation is required to be done for a better result in the teaching and learning process in the classroom.

Cunningsworth (1998) stated that evaluating a textbook is helpful to adapt the suitability of a textbook with certain requirements including the goals of the students, the backgrounds of the students, the available sources, etc. The ability to evaluate textbook for appropriateness must be a teachers' premier skill since a textbook can have an impact on the learning results in the teaching and learning process. A good English textbook should correspond to the learning objectives according to the syllabus, cover all four basics of English skills in the form of content and practice, interesting, and have various exercises to provide different levels of learning (Ur, 2009; Richards, 2001). Thus, English language textbook for twelfth grade students by the Indonesian Ministry of Education and Culture can be categorized as a good English textbook if it meets those criteria. However, teachers should consider that there is no best textbook for groups of students. Teachers should not rely too much on a textbook but develop material or make other interesting material with their own skills. Teachers who rely too much on a textbook usually will not encourage enough rough-tuned input or output practice (Harmer, 1996).

\section{Reading Comprehension}

Reading is centrally a process to comprehend what the author intended to express in writing (Grabe, 2009). Reading comprehension is defined as the process of building meaning from combining the reader's background knowledge with the additional information from a text, drawing the meaning of words, and connecting all of them to create meaning (Nunan, 2003). Johnson (2008) said that reading comprehension is the use of strategies in reading to retrieve information and create meaning of texts conducted by the readers. Strategies that are applied by the readers depend on the readers' purpose in reading comprehension.

According to Burmeister (1974), great reading competence requires several significant components. The student should master several indicators that can indicate their reading skill such as understanding reference in the reading text, understanding main idea, understanding the tone of the text, understanding the message of the story, understanding topic of the text, understanding vocabulary, understanding logical inference, distinguishing between general idea and topic sentence, making an accurate prediction, making restatement, and understanding grammar. Djiwandono (2008) stated that the indicators in 
the assessment of reading comprehension are as follows: understanding the meaning of word by word related with the text, understanding the structure or organization on the text and relation of every paragraph, finding the main idea on the text, understanding the topic of the text, ability to answer some explicit question, ability to make inference about the text, understanding the meaning of the word and expression to understand the literature meaning, understanding the writer's intention and message on the text. According to Grellet (1998), students must have the following competences in mastering reading skill. The list of the competences is as follows: understanding reference, distinguishing the main idea from supporting details, deducing the meaning and the use of unfamiliar lexical items, understanding conceptual meaning, understanding the communicative function, understanding explicit stated information, understanding information when not explicitly stated, recognizing the script of a language, interpreting a text by going outside it. Thus, there are six indicators of reading skill, they are: topic, main idea, reference, explicit meaning, implicit meaning, and contextual meaning.

\section{Higher Order Thinking Skill}

There are three classifications regarding the definition of the higher order thinking: (1) those that define higher-order thinking in terms of the transfer, (2) those that define it in terms of critical thinking, and (3) those that define it in terms of problem solving (Brookhart, 2010). Resnick (1987) said that higher order thinking skill is the ability to elaborate the given material, making inferences beyond what is explicitly presented, building sufficient representations, analyzing, and constructing relationships. Moreover, Anderson and Krathwohl (2001) stated that higher-order thinking skills (HOTS) are the skill involving the process of analyzing, evaluating, and creating. Thus, HOTS incorporating problem solving, critical and creative thinking skill can be defined as skill that involves the process of analyzing, evaluating, and creating. Mayer (2002) stated that higher order thinking skill provides a learning vision that develops broader than just gaining knowledge but also being capable to apply the knowledge gained in various new contexts, encourages the meaningful learning, and actively involves students in the process of building meaning. It shows that when learning and improving higher order thinking skill, the teachers let the students activate their thoughts and ideas. Those processes are for encouraging the thoughts and reasoning some ideas which direct to greater processing of information in the learning process.

In education, many experts construct taxonomies according to their respective opinions. The most widely known is Bloom's taxonomy.

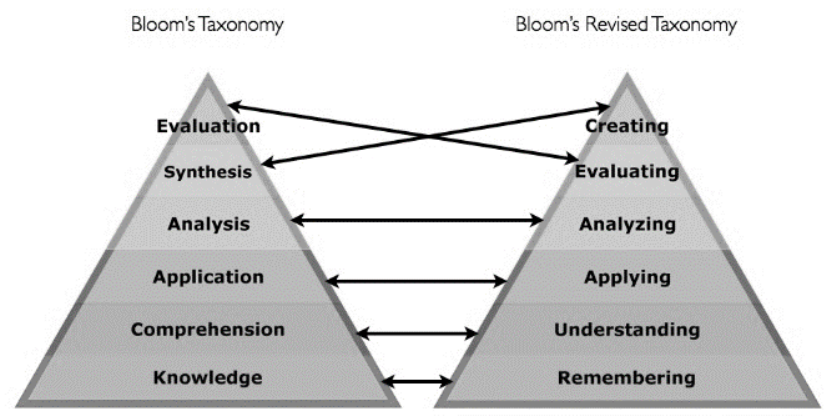

Figure 1. The original and revised version of Bloom's taxonomy (Anderson and Krathwohl, 2001) 
Figure 1 shows the differences are only shown in the word-used and the rearrangement of the last two domains: synthesis and evaluation which change into evaluating and creating. Those two skills are reordered because they are considered that the students need to be able to criticize and check information before they produce and generate some results. The remaining level of cognitive domains that require the students to accomplish thinking and reasoning processes more complicated than memorization is included in the higher order thinking level of cognitive domains in Bloom's taxonomy. The higher order thinking skill in the revised Bloom's taxonomy looks like: (1) analyzing level means breaking apart the information into smaller ideas and revealing the relation of those ideas; (2) evaluating level accommodates checking and critiquing the value of material based on certain criteria; and (3) creating level includes generating, planning, and producing the new structure from the different components.

The questions in reading comprehension exercises should be proportional among the low level cognitive questions and high level cognitive questions. The questions should be proportional because low and high cognitive questions are integrative (Freahat and Smadi in Ulum, 2016). Sukiman (2012) stated that the great composition for higher order thinking skill questions is $50 \%$ of the total number of questions. For details, the analyzing level questions should have the highest proportion that is $20 \%$ while evaluating and creating level have the same proportion that are $15 \%$ respectively. Thus, questions in reading comprehension exercises should be arranged in a balanced proportion between the higher and lower level of thinking questions.

\section{METHOD}

The research used the descriptive analytical method of research, which refers to content analysis. Hsieh and Shannon (2005) said that content analysis is a research method for the subjective interpretation of the content of the text data through the systematic classification process of coding and identifying themes or patterns. The researcher analyzed the content of the textbook, particularly the reading comprehension exercise in the textbook. The researcher used the checklist table to collect the data. The researcher collected and listed all of the essay questions of the reading exercises that come after every reading text. Then, the researcher used the checklist table form to analyze and compare the distribution of the higher order thinking skill based on the revised version of Bloom's taxonomy and the indicators of reading skill in the reading comprehension exercises of the English language textbook for twelfth grade students by Indonesian Ministry of Education and Culture. Then, the researcher counted the total number to find out the exact number of the distribution of the higher order thinking skill and the reading skill indicators. The results of the analysis were presented in the form of a percentage. Finally, the researcher interpreted and concluded the results of the data analysis by describing it qualitatively.

\section{RESULTS AND DISCUSSION}

\section{Higher Order Thinking Skill in Reading Comprehension Exercises}

In reading comprehension exercises of the English language textbook for twelfth grade students by Indonesian Ministry of Education and Culture, the higher order thinking skill which consists of analyzing, evaluating, and creating level only gets 10 questions out of 67 essay reading comprehension questions. The analyzing skill (C4) gets 4 items, the evaluating skill (C5) gets 6 items, and there is no question of creating skill (C6). The checklist table also shows that the distribution of the lower order thinking skill obtains $85.07 \%$ while the higher order thinking skill only obtains $14.93 \%$. Further, table 1 explains the percentage and the distribution of each skill in the higher order thinking skill in the 
reading comprehension exercise of the English language textbook for twelfth grade students by Indonesian Ministry of Education and Culture.

Table 1. The Distribution of the Higher Order Thinking Skill in Reading Comprehension Exercise

\begin{tabular}{cccc}
\hline No. & $\begin{array}{c}\text { Higher Order } \\
\text { Thinking Level }\end{array}$ & Reading Questions & Percentages \\
\hline 1 & Analyzing & 4 & $5.97 \%$ \\
2 & Evaluating & 6 & $8.96 \%$ \\
3 & Creating & 0 & $0 \%$ \\
& Total & $\mathbf{1 0}$ & $\mathbf{1 4 . 9 3 \%}$ \\
\hline
\end{tabular}

Table 1 shows that from total of 67 essay reading comprehension questions in the textbook, the analyzing skill obtains 4 questions out of 67 questions or $5.97 \%$, the evaluating skill obtains 6 questions out of 67 questions or $8.96 \%$, and there is no questions belongs to the creating skill. Based on the distribution of the higher order thinking skill, it shows that the evaluating skill obtains the highest distribution among the three skills while the analyzing skill in the second place and the creating skill obtains null distribution.

By considering at the percentage between the three skills in the higher order thinking skill, it looks like the distribution of the higher order thinking skill is improperly treated in the reading comprehension questions. The analyzing skill questions should have the highest proportion that is $20 \%$ while evaluating and creating level have the same proportion that are $15 \%$ respectively (Sukiman, 2012). Meanwhile, the percentage of the three skills in higher order thinking skill in the textbook are under the required proportion. Moreover, the total number of higher order thinking questions in the textbook does not reach $50 \%$ of the total number of questions.

Furthermore, table 2 and table 3 add the essay reading comprehension questions based on each skill so the types of the questions which belong to the three skills in the higher order thinking skill could be clearly seen. Table 2 is the table for the question list of the analyzing skill.

Table 2. The Question List of Analyzing Skill

\begin{tabular}{ccl}
\hline Ch. & No. & \multicolumn{1}{c}{ Questions List of Analyzing Skill } \\
\hline 7 & 2 & $\begin{array}{l}\text { What was probably the main reason for holding the conference? } \\
9\end{array}$ \\
7 & $\begin{array}{l}\text { Do you think the steps have to be put in order? Why do you think } \\
\text { so? }\end{array}$ \\
10 & 9 & $\begin{array}{l}\text { Do you think the text is originally finished or it is continued other } \\
\text { information? }\end{array}$ \\
& 10 & $\begin{array}{l}\text { What further information do you need so that you can really operate } \\
\text { Photoshop? }\end{array}$ \\
\hline
\end{tabular}

Table 2 shows that there are 4 questions of the analyzing skill. The highest distribution of questions that belong to the analyzing skill is from chapter 10 with 2 questions while chapter 7 and chapter 9 distribute the same number, 1 question. From those 4 questions, the types of analyzing questions are fairly various. There is a question of the analysis question with the reasoning questions type, "What was probably the main reason for holding the conference?" in chapter 7. There is also a question in chapter 9 which asks 
"Do you think the steps have to be put in order?", this question is the analyzing question type that asks students to determine how ideas are connected to one another. In chapter 10, there are two analyzing questions "Do you think the text is originally finished or it is continued to other information?" and "What further information do you need so that you can really operate Photoshop?", those are the same type of analyzing questions which ask students to connect supporting statements to get the conclusion.

Table 3 explains the essay reading comprehension questions that belong to the evaluating skill.

Table 3. The Question List of Evaluating Skill

\begin{tabular}{ccl}
\hline Ch. & No. & \multicolumn{1}{c}{ Question List of Evaluating Skill } \\
\hline 2 & 8 & $\begin{array}{l}\text { If you were an aircraft factory staff, what would you say to offer help } \\
\text { for your visitors. What if.......... }\end{array}$ \\
4 & 9 & $\begin{array}{l}\text { Do you think that Lilis is confident about her competence? How do } \\
\text { you know? }\end{array}$ \\
5 & 4 & $\begin{array}{l}\text { Why do you think living in an apartment is getting popular? } \\
6\end{array}$ \\
& 9 & $\begin{array}{l}\text { What do you think about the acting governor's response to the parents' } \\
\text { protests? }\end{array}$ \\
7 & 4 & $\begin{array}{l}\text { How important was the conference for Indonesia? } \\
\text { What do you think about the mayor's concept on municipal waste } \\
\text { management? }\end{array}$ \\
\hline
\end{tabular}

Based on table 3, there are 6 questions out of 67 questions. The highest distribution of questions that belong to the evaluating skill is from chapter 7 with 2 questions. Chapter 2 , chapter 4 , chapter 5 , and chapter 6 distribute the same number, 1 question. This skill obtains percentage $8.96 \%$. It is the highest number among the three skills in the higher order thinking skill although if it is compared to the other six domains, it is still considered to have small distribution. It might happen because evaluating skill is one of the most critical thinking skill therefore it is such a challenging to answer (Daiek and Anter, 2004). Hence, evaluating skill questions could guide students to evaluate some ideas in various kinds of questions. From those 6 questions, almost all of the questions are asking the students' judgments and students' responses about something. The example of the question is "What do you think about the mayor's concept on municipal waste management?" which demands students to make judgments about the value of ideas based on the standards.

Moreover, the third skill is creating skill which is the most critical thinking skill among the three skills in higher order thinking skill. However, the result shows that there is no reading comprehension question among 67 questions in the English language textbook for twelfth grade students by the Indonesian Ministry of Education and Culture which belongs to the creating skill. Though, creating skill is essential to prepare students for college life because the lecture will ask the students to think about discrete items of information with the intention to reach a greater understanding (Daiek and Anter, 2004).

Reading comprehension exercise in the textbook ideally contains a great proportion of higher order thinking skill questions to promote the students' higher order thinking skill. The higher order thinking skill (HOTS) questions should have a proper and balanced proportion with the lower order thinking skill (LOTS) questions because the higher order thinking skill questions are useful as a stimulus to improve students' cognitive skill. Freahat and Smadi (in Ulum, 2016) also stated, "One should consider the nature of the relationship between low and high cognitive questions. This relationship can be described as integrative. Low level cognitive questions can improve the acquisition of 
factual knowledge and the fundamentals for achieving high level cognitive skills. Instead, high level cognitive questions are effective tools for stimulating thinking and developing other cognitive skills such as problem solving and decision making." Higher order thinking skill questions in reading comprehension exercises are also very beneficial as a strategy to improve students' thinking abilities. Thus, good readers use high level thinking strategies to think about and control their reading before, during, and after reading a selection. Students who do not use HOTS to the fullest usually have low achievement in reading (Marier, 2000). However, higher order thinking skill has low proportion in the reading comprehension exercises questions in English language textbook for twelfth grade students by Indonesian Ministry of Education and Culture. The explanation clearly reveals that English language textbook for twelfth grade students by Indonesian Ministry of Education and Culture still does not optimally contain higher order thinking skill in the reading comprehension exercises. This research has result that is similar to all the studies discussed in the relevant studies, that is the number of questions with lower order thinking skill is higher than the number of questions with higher order thinking skill. The textbook only contains analyzing skill and evaluating skill in higher order thinking skill. Besides that, in the reading comprehension exercises in the textbook, the number of questions that require the students' lower order thinking skill to work on is more dominating when compared to the higher order thinking skill.

\section{The Indicators of Reading Skill in the Reading Comprehension Exercises}

In reading comprehension exercises of the English language textbook for twelfth grade students by Indonesian Ministry of Education and Culture, the distribution of the indicators of reading skill which consist of topic, main idea, reference, explicit meaning, implicit meaning, and contextual meaning are unequal. From the 67 essay reading comprehension questions in the English language textbook for twelfth grade students by the Indonesian Ministry of Education and Culture, not all of the indicators of reading skills are assessed from those questions. There are only 3 indicators of reading skills assessed in the questions. Those 3 indicators are topic, explicit meaning, and implicit meaning. Further, table 4 explains the percentage and the distribution of each skill in the indicators of reading skill in the reading comprehension exercise of the English language textbook for twelfth grade students by Indonesian Ministry of Education and Culture.

Table 4. The Distribution of the Indicators of Reading Skill in Reading Comprehension Exercise

\begin{tabular}{cccc}
\hline No. & $\begin{array}{c}\text { The Indicators of } \\
\text { Reading Skill }\end{array}$ & Reading Questions & Percentages \\
\hline 1 & Topic & 1 & $1.49 \%$ \\
2 & Main Idea & 0 & $0 \%$ \\
3 & Reference & 0 & $0 \%$ \\
4 & Explicit Meaning & 35 & $52.24 \%$ \\
5 & Implicit Meaning & 31 & $46.27 \%$ \\
6 & Contextual Meaning & 0 & $0 \%$ \\
\hline
\end{tabular}

There is only 1 question out of 67 essay reading comprehension questions that belongs to topic, it gets percentage $1.49 \%$, while explicit meaning with percentage $52.24 \%$ gets 35 questions out of 67 essay reading comprehension questions, slightly different from explicit meaning, implicit meaning gets 31 questions with percentage $46.27 \%$. 
The first indicator assessed from the questions in reading comprehension exercise in this textbook is topic. Understanding the topic of the text is one of the competencies that must be achieved as an indicator of good student reading skill (Burmeister, 1974). However, there is only 1 question that assesses topic indicator in reading comprehension exercises in this textbook. In chapter 9, students are given a text then given a question "What is the text talking about?" which requires students to identify the topic of the text that given. 1 question out of 67 questions counts too little to be able to train and assess students' reading skill in assessing a topic of a text. The authors should add more questions to assess the topic indicator. Questions to assess topic indicators can be varied, they can be direct questions or indirect questions, for example: "What is the topic of the passage?" or "The text mainly talks about...".

The second indicator assessed from the questions in reading comprehension exercise in this textbook is explicit meaning. The answers to the questions in reading comprehension exercises to assess explicit meaning indicator can be found explicitly in the words of the text. The example of the question is "If you visit Seattle, the first thing to do is..." which is firstly followed by a text explaining about the things to do when visiting Seattle. From the text provided, students can easily find the answer. The number of questions that assess this indicator is the highest, 35 questions or $52.24 \%$. It may occur because explicit meaning questions are important for assessing students' basic abilities in understanding a text before they reach the more difficult level of questions. This is supported by Pearson and Johnson (1972) who stated that explicit meaning questions proficient to ensure that the students have understood the basic or surface meaning of the text. Explicit meaning questions also support the development of higher level comprehension skills, such as inference making (Blything, 2019). Thus, explicit meaning questions in reading comprehension exercise are important to be able to assess students' understanding of the text in a fundamental way and to train students to be able to answer questions that require a deeper understanding.

The third indicator assessed from the questions in reading comprehension exercise in this textbook is implicit meaning. The questions in the reading comprehension exercises to assess this indicator require the readers to make a conclusion based on information in the text. For example, presented a text about Indonesia opens regional recycling conference then presented a question related to the text such as "How important was the conference for Indonesia?" which can be answered when students read the text and understand the text as well as the question. The number of questions that assess this indicator is quite a lot, 31 questions or $46.27 \%$, almost half of the questions in the reading comprehension exercises in this textbook assess this indicator. It might happen because implicit meaning questions are very useful for measuring students' reading skill in a deeper understanding of the text presented. Students can only answer implicit meaning questions if they really understand the text presented, because the questions used to assess implicit meaning indicator can only be solved if the students are able to elaborate conclusions from the text to interpret what is not explicitly written in the text. Implicit meaning questions are considered more complicated than explicit meaning questions because implicit meaning questions require a literal understanding of what is written explicitly as well as an inferential understanding of what is only suggested in the text, students need to integrate the pieces of information across the sentences (Alderson, 2000).

In addition to the 3 indicators of reading skill that have been assessed in reading comprehension exercises in English language textbook for twelfth grade students by Indonesian Ministry of Education and Culture, there are still 3 other indicators of reading skill that have not been assessed in reading comprehension exercises in this textbook namely main idea, reference, and contextual meaning. The 3 indicators of reading skill that 
have not been assessed are also important indicators to assess the extent of student mastery in reading skill (Burmeister, 1974; Djiwandono, 2008; Grellet, 1998).

The questions in the reading comprehension exercises supposedly assess all indicators of reading skill in order to be useful to train and assess students' reading skill appropriately. To ensure whether the students do make progress in reading comprehension or not, an assessment should be done. One of the assessments which can be done by the teacher is by looking at students' responses in answering questions in reading comprehension exercises. Therefore, the questions in reading comprehension exercises must assess all indicators that can indicate the students' reading skill: topic, main idea, reference, explicit meaning, implicit meaning, and contextual meaning (Burmeister, 1974; Djiwandono, 2008; Grellet, 1998). Besides, the indicators of reading skill must be implemented in reading comprehension exercises questions to train students to achieve good reading skill. If the questions in reading comprehension exercises do not assess indicators of reading skill properly, students will have difficulty mastering reading skill because to master reading skill students need to practice reading exercise. It is supported by Simanjuntak (1988) who stated that one of the principles of learning reading is reading requires practice. However, the indicators of reading skill are not fully assessed from the questions in the reading comprehension exercises in English language textbook for twelfth grade students by Indonesian Ministry of Education and Culture. From the explanation, it clearly shows that English language textbook for twelfth grade students by Indonesian Ministry of Education and Culture only assesses 3 indicators of reading skill in the reading comprehension exercises questions namely topic, explicit meaning, and implicit meaning. From those 3 indicators, the indicator highlighted from the reading comprehension exercises questions in the textbook is explicit meaning. The 3 other indicators of reading skill namely main idea, reference, and contextual meaning have not been assessed from reading comprehension exercises questions.

\section{CONCLUSION}

From the findings, it can be concluded that English language textbook for twelfth grade students by Indonesian Ministry of Education and Culture does not properly cover, treat, and distribute higher order thinking skill in the reading comprehension exercises. The same thing also happened to indicators of reading skill in the reading comprehension exercises, the questions in the reading comprehension exercises only assess half of the overall reading skill indicators. It means that the textbook does not put a significant concern regarding the higher order thinking skill and the indicators of reading skill in the reading comprehension exercises. Therefore, the author is suggested to add and complete higher order thinking skill questions to achieve a balanced proportion between lower level questions and higher lever questions because in the reading comprehension exercises in the textbook the lower order thinking skill questions are still more dominating compared to the higher order thinking skill questions. The author also should add and complete the questions in reading comprehension exercises to assess all of the reading skill indicators because the indicators of reading skill have not been fully assessed in the reading comprehension exercises. For teacher, they should combine the use of English language textbook for twelfth grade students by Indonesian Ministry of Education and Culture with additional reading comprehension exercises from other sources and develop reading comprehension exercises questions in the textbook by adding their own higher order thinking skill questions especially creating skill that has not been included and their own questions about main idea, reference, and contextual meaning that have not been assessed in the textbook. For the other researchers, they may analyze reading comprehension 
exercises from other English textbooks using the same theory and compare them to discover a better textbook for the teacher or the school.

\section{REFERENCES}

Airasian, Peter W. and Russell, Michael K. (2008).Classroom Assessment: Concepts and Applications. Boston: McGraw-Hill. $6^{\text {th }}$ Ed.

Al Raqad, Yahya. and Ismail, Hanita. (2018). Analyzing the Reading Questions of AP12 Textbook According to Bloom's Taxonomy. International Journal of Education, Psychology and Counselling 3 (22), 84-94.

Alderson, J.C. (2000). Assessing Reading. New York: Cambridge University Press.

Anderson, L. W., \& Krathwohl, D. R. (2001). A taxonomy for learning, teaching, and assessing: A revision of Bloom's taxonomy of educational objectives. New York: Longman.

Assaly, Ibtihal R. and Smadi, Oqlah M. (2015). Using Bloom's Taxonomy to Evaluate the Cognitive Levels of Master Class Textbook's Questions. English Language Teaching Journal 8(5), 100-110.

Blything, Liam. (2019). Question Asking During Reading Comprehension Instruction: A Corpus Study of How Question Type Influences the Linguistic Complexity of Primary School Students' Responses. Reading Research Quarterly 0(0), 1-30.

Brookhart, M. (2010). How to Asses Higher-Order Thinking Skills in Your Classroom. Alexandria: ASCD Member Book.

Burmeister, L. E. (1974). Reading Strategies for Secondary School Teachers. MA: Addison-Wesley.

Chalak, Azizeh. and Mizbani, Maryam. (2017). Analyzing Reading and Writing Activities of Iranian EFL Textbook Prospect 3 Based on Bloom's Revised Taxonomy. Journal of Appplied Linguistics and Language Research 4 (2), 13-27.

Cunningsworth, Alan. (1998). Choosing Your Coursebook. Oxford: Macmillan Publisher.

Daiek, Deborah and Anter, Nancy. (2004). Critical Reading for College and Beyond. Boston: The McGraw-Hill Companies.

Djiwandono, M. Soenardi. 2008. Tes Bahasa: Pegangan bagi Pengajar Bahasa. Jakarta: Indeks.

Grabe, William. (2009). Reading in a Second Language. New York: Cambridge University Press.

Grellet, Francoise. (1998). Developing Reading Skills: A Practical Guide to Reading Comprehension Exercises. Cambridge: Cambridge University Press.

Harmer, Jeremy. (1996). The Practice of English Language Teaching. New York: Longman Publishing.

Hsieh, H. F. \& Shannon, S. E. (2005). Three Approaches to Qualitative Content Analysis. Qualitative Health Research,15 (9), 1277-1288.

Johnson, P. A. (2008). Teaching Reading and Writing (A Guidebook for Tutoring and Remediating Students). New York: Rowman \& Littlefield Publishers, Inc.

Marier, R. (2000). Reading Comprehension Techniques for Improving Students' Success in Extracting Useful Knowledge from Text. New Jersey: Pearson Education, Inc.

Maulia, Kembara, et.al. (2018). Research-based Lectures to Improve Students' 4C (Communication, Collaboration, Critical Thinking, and Creativity) Skills. Advances in Social Science, Education and Humanities Research (306), 22-26.

Mayer, Richard. (2002). Theory Into Practice: Rote Versus Meaningful Learning. New York: The H. W. Wilson Company 
Nunan, David. (2003). Language Teaching Methodology. London: Prentice Hall International.

Pearson, P. D. \& Johnson, D. D. (1972). Teaching Reading Comprehension. New York: Holt, Rinehart \& Winston.

Resnick, L. (1987). Education and Learning to Think. Washington, DC: National Academy Press.

Richards, Jack C. (2001). Curriculum Development in Language Teaching. Cambridge: Cambridge University Press.

San, Kaung Myat. (2019). The Thinking Levels Demanded in Reading Activities in The Coursebook Global A2+. International Journal of Education and Research 7 (5), 23-36.

Simanjuntak, E. G. (1988). Developing Reading Skill for EFL Students. Jakarta: Departemen Pendidikan dan Kebudayaan.

Sukiman. (2012). Pengembangan Sistem Evaluasi. Yogyakarta: Insan Madani.

Ulum, O. G. (2016). A Descriptive Content Analysis of the Extent of Bloom's Taxonomy in the Reading Comprehension Questions of the Course Book Q: Skills for Success 4 Reading and Writing. The Qualitative Report, 21 (9), 1674-1683.

Ur, Penny. (2009). A Course in Language Teaching: Practice and Theory. Cambridge: Cambridge University Press. 